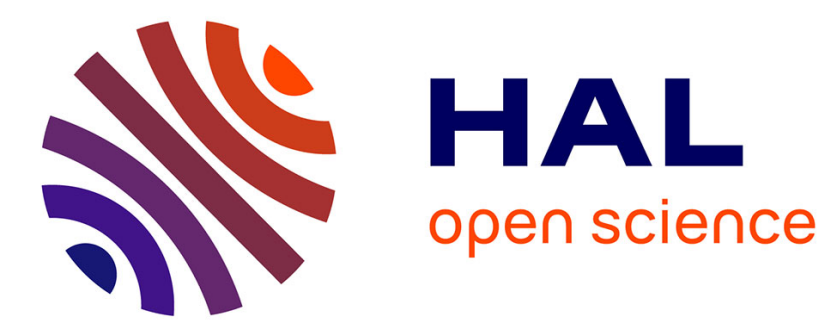

\title{
GaAs LASER RHEUMATISMAL BIOSTIMULOTHERAPY
}

\author{
A. Podoleanu, C. Antipa
}

\section{To cite this version:}

A. Podoleanu, C. Antipa. GaAs LASER RHEUMATISMAL BIOSTIMULOTHERAPY. Journal de Physique IV Proceedings, 1991, 01 (C7), pp.C7-231-C7-234. 10.1051/jp4:1991759 . jpa-00251001

\section{HAL Id: jpa-00251001 https://hal.science/jpa-00251001}

Submitted on 1 Jan 1991

HAL is a multi-disciplinary open access archive for the deposit and dissemination of scientific research documents, whether they are published or not. The documents may come from teaching and research institutions in France or abroad, or from public or private research centers.
L'archive ouverte pluridisciplinaire HAL, est destinée au dépôt et à la diffusion de documents scientifiques de niveau recherche, publiés ou non, émanant des établissements d'enseignement et de recherche français ou étrangers, des laboratoires publics ou privés. 


\title{
GaAs LASER RHEUMATISMAL BIOSTIMULOTHERAPY
}

\author{
A.Gh. PODOLEANU and C.S. ANTIPA* \\ Physics Department, Polytechnic Institute of Bucharest, Spl. Independentei 313, Bucharest, Roumania \\ *Titan Clinical Hospital, 49-51 Muncii Av., Bucharest, Roumania
}

\begin{abstract}
The paper deals with the construction of a pulsed laser diode generator for medical purposes, using avalanche transistors. The promising results obtained with such a generator in rheumatismal biostimulotherapy are also discussed.
\end{abstract}

\section{1 - Introduction}

There are known different diagrams used to excite the pulsed laser diodes. These diagrams deliver high current pulses of $10-40 \mathrm{~A}$ and with a very short width of $50-200 \mathrm{~ns} / 1 /$. The basic diagram consists in a switching element and in a charge accumulator. Depending on the switching element type, there are known electro-mechanical, nanosecond thyristor, very fast switching transistor or avalanche transistor generators.

The most widespread diagrams use nanosecond thyristors. They assure both low resistance in the on state and a great value for the generator life time as well. But, a very fast thyristor may be often an electronic component which is comparable in price with the laser diode. As an alternative to the thyristor diagram, we put into order a less expensive scheme based on avalanche transistors $/ 2 /$.

\section{2 - Avalanche transistor generator}

The avalanche regime is quite nonspecific for transistor. The catalog does not say anything in this respect. In consequence, we had to check many transistor types. In this way, we found BC 107, BC 171, 2N1711, 2N6653, 2N6654 very suitable for this kind of operation. Some samples of BC 107, BC 171, 2N1711 may assure currents up to $10 \mathrm{~A}$ wheareas 2N6653 or $2 \mathrm{~N} 6654$ may deliver currents in excess of $50 \mathrm{~A}$. Table 1 indicates the values of the currents delivered by these avalanche transistor types in a load resistor of $2.2 \Omega$ and for a collector capacitor of $1,8 \mathrm{nF}$.

The table 1 stresses out a large dispersion of the parameters. We also noticed a very reduced stability of the parameters and a very reduced life time in consequence when operating at high currents, i.e. when a low load resistance was used. So, as the time runs on, the breakdown voltage decreases and the amplitude of the pulsed current as well. This may be explained by the local damages which appear in the transistor junction. Thus, points accidentally appear in the junction, where the depletion layer is thinner. In these points, the junction breakthrough first and the current flow will preferentially use them. In consequence, the area used for carrier transfer reduces considerably and the current value as well.

Table 1. Transistor performances in avalanche regime of operation

\begin{tabular}{|c|c|c|}
\hline Transistor Type & Voltage (V) & Peak current (A) \\
\hline BC 107, BC 171, 2N1711 & $150-280$ & $2-10$ \\
\hline 2 N 6653, 2N6654 & $580-820$ & $8-55$ \\
\hline
\end{tabular}

In order to avoid these destructive effects, we may limit the discharge current. So, a value of the load resistance in excess of $5 \Omega$ increases the transistor's life time considerably. 
Taking into account the medical destination of the equipment, it has to meet some requirements. So, it has to be light, easy to move on the patient's skin and to accomplish safety requirements. Thus, a too high voltage source for a device in direct touch with the patient and the doctor is undesireble. This prevents the usage of other transistor types which have breakdown voltages in excess of $1 \mathrm{kV}$ and of the serial connection of the transistors as well.

We constructed two avalanche transistor based generator variants. One variant uses 8 very low power transistors (BC107) in parallel and another one uses only one power transistor 2 N6654. The principle diagram for both variants is shown in fig. 1. The first transistor, $T_{9}$, operates also in avalanche regime and delivers very short and high pulses for the power stage. This stage consists either in many small power transistors or in one or in almost two power transistors. The power supply $\mathrm{E}_{1}$ has $80-150 \mathrm{~V}$, while the power supply $\mathrm{E}_{2}$ may have $150-200 \mathrm{~V}$ or $600-800 \mathrm{~V}$ depending on the avalanche transistor type used in the power stage.



Fig. 1. Detailed electronic diagram.

For one transistor BC 107A in the final stage and a $2.2 \Omega$ value for the emitor resistance, we measured the pulse full width at half maximum (FWHM) $\tau$ and the pulse peak current I dependences on the collector capacitance value. These results are shown in fig. 2 for $190 \mathrm{~V}$ power supply voltage.

When many transistors are put in parallel, we have to match their parameters. The breakdown voltage and the delay time usually varie from one transistor to another. This prevents a correct addition of the pulses delivered by each transis tor and results in a multiple pulse operation, or in a lower amplitude and wider pulses. Different methods were issued in order to prevent the temporal splitting of the pulses from appearing. One of them [3] uses potentiometers for each collector resistor to balance the values of the transistors breakdown voltage. This would deteriorate the dimension and the weight parameters of the generator.

We obtained very good results by using another method instead. We used very similar 8 sample of transistors of BC $107 \mathrm{~A}$ prelevated from the same production sample of the IPRS - Bucharest) company. In this way, a very sharp pulse of $30 \mathrm{~A}$ pulse peak value with 100 ns FWHM resulted (fig. 3). The photodetected signal was measured using a very fast avalanche photodiode (TIXL - 55).

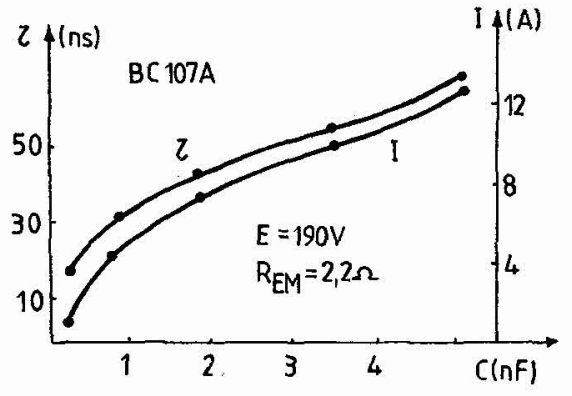

Fig. 2. Dependences of the pulse peak I and of the FWHM $r$ on the collector capacitance.

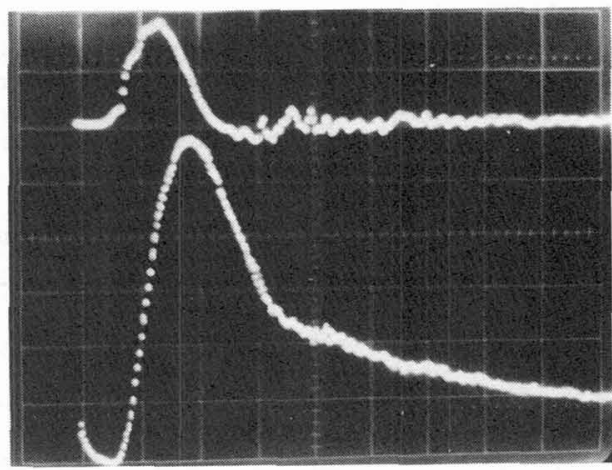

Fig. 3. Diode laser current (top) and the photodetected pulse (bottom). H: $100 \mathrm{~ns} / \mathrm{div}$; $\mathrm{V}$ top: $15 \mathrm{~A} / \mathrm{div}$; V bottom: $200 \mathrm{mV} /$ div. 


\section{3 - Clinical study of the rheumatismal biostimulotherapy application}

A generator of the type presented above was used to excite an AGALP 3 - 225 (IFTAR - Bucharest) laser diode. These diodes operate on $895 \mathrm{~nm}$ and emit $20 \mathrm{~W}$ under $30 \mathrm{~A}$ excitation. A constant period of $1 \mathrm{~ms}$ for the modulation signal was used. This results in a $3 \mathrm{~mW}$ average optical power.

The patients were divided into two groups: A, treated only by laser stimulotherapy, consisting in 41 peoples (24 women between 28 and 69 years old and 17 men between 30 and 74 years); B, treated by usual therapy (anti-inflamatory, non steroidal drugs and physical means), consisting in 24 peoples (15 women between 32 and 68 years old and 9 men between 35 and 72 years old). We tried to arrange a similar structure about sex, age and level of the disease gravity for the two groups. We have studied the biostimulotherapy influence onto painful shoulder ( 9 patients in A group and 5 in B group), sciatics (15 and 9 respectively), knee arthrosis (10 and 6 respectively), and coxarthrosis ( 7 and 4 respectively).

The patients from A group did not receive drugs either before ( 10 days prior the treatment), or after the laser therapy. An operating time of 2-6 minutes was used per point for $6-20$ sessions. The treatment duration was individually established depending on the clinical answer $/ 4,5 /$. The lased diode head was put in direct touch with the patient's skin in a number of points (acupunctural, loco - dolenti and other points) for each disease.

The results are shown in the table 2 (expressed in number of hilled patients) and in the fig.4 (expressed in percentage from total number).

Table 2. Comparative presentation of the laser therapy (A) and of the classical therapy (B) results

\begin{tabular}{|l|c|c|c|c|c|c|}
\hline \multirow{2}{*}{ Disease } & \multicolumn{2}{|c|}{ Number } & \multicolumn{4}{c|}{ Treatment Efficiency } \\
\cline { 2 - 7 } & \multicolumn{2}{|c|}{} & \multicolumn{2}{c|}{ just after } & 4 months later \\
\cline { 2 - 7 } & gr. A & gr. B & gr. A & gr. B & gr. A & gr. B \\
\hline Painful Shoulder & 9 & 5 & 8 & 3 & 8 & 3 \\
\hline Sciatics & 15 & 9 & 12 & 6 & 11 & 5 \\
\hline Knee Arthrosis & 10 & 6 & 9 & 4 & 7 & 3 \\
\hline Coxarthrosis & 7 & 4 & 6 & 3 & 5 & 3 \\
\hline
\end{tabular}



Fig. 4. Percentage evaluation of the treatment efficiency for different diseases, just after the treatment and 4 months later. 
In order to evaluate the hipothetical biological and haematological side - effects of laser, we investigated the patients state of health before, just after the treatment and 4 month later. This investigations consisted in physiological analysis (transaminases, cholesterol, lipids, acid and alkaline phosphatases, fibrinogen, glucose, tymol, urea creatinine, uric acid, calcium, globulins, total proteins) and haemathological analyses (haemoglobin, leukocytary formula, trombocytes, ESR). The clinical efficiency was correlated with the subjective pain and the functional impotency: stationar, little improvement, important improvement, disappearence, just after the treatment and 4 months later (in this time interval, the patients were did not treated by no means).

We could notice an important improvement or disolution of the pain and of the functional impotency. It is obvious that for all the mentioned diseases, the laser biostimulation results are better than those obtained by clasical therapeutical means. Thus, just after the treatment, the hilling percentages are between $80-90$ for the A group in comparison with a value of 60-70 for the B group. 4 months later, the percentages are 70-88,9 and 50-75 respectively. The 4 months later results are similary for the coxarthrosis only.

We did not notice significantly different effects of the laser therapy correlated with age and sex.

For the A group we did not notice any side-effects, wheareas for group B, there were 14 patients with the well - known side-effects and for three of them we had to change the administrated drugs.

The analyses (haematological and biological) did not change significantly either just after the treatment or 4 months later. This is another argument for the absence of toxicity of the laser biostimulation $/ 6 /$.

\section{4 - Conclusions}

A versatile and less expensive avalanche transistor generator for pulsed laser diodes was built-up. This generator was used in the treatment of painful shoulder, sciatics, knee arthrosis and coxarthrosis.

1. The hilling efficiency when using laser therapy was better than in the case of classical therapy by drug administration, just after the treatment and $\mathbf{4}$ months later as well.

2. No side effects could be recordered either during the treatment or later for the patients from the laser group (A).

3. No relevant differences apperead in biological and haematological analysis results for the same group (A).

Much more efforts have to be done in evaluating the laser radiation influence. Thus, studies regarding the laser power influence, the treatment efficiency dependence on the chosen zone of the patient's skin, the time used for stimulating of each point and the number of points, are under the way.

\section{5 - Acknowledgmens}

The partially support of Soros Foundation - Open Society Romania and of the Ianus - Bucharest Company in sponsoring the participation of two authors (A. Podoleanu and C. Antipa) in the conference Laser M2P are gratefully aknowledged.

\section{References}

1/ ITT Pulse Generators for Laser Diodes, 6340/683 E, 1973.

12/ PODOLEANU A. Gh., vol Annual Semiconductor Conference, CAS - (1990), p.361 - 364.

13/ SANDU D. D., "Modern Problems of Pulse Technique", Romanian Acad. Publishing House, (1980), p.205 - 210.

14/ SUTEANU S., OANCEA P., MACARIE O., Stud. Cercet. Fiz., 40, (1988),p. 599 - 612.

15/ GRITTEN C., FRANCHIMOND P., Rev. Med. Liege, 6, (1987), p. 230 - 235.

6/ PARRISH J. A., Photomedicine: Potentials for Lasers. An Overview, in "Lasers in Photomedicine and Photobiology", PRATESI R. and SACCHI C.A., edit,, Springer Verlag - Berlin, (1980), p. 2 - 22. 